Абдусалалов M.M. Сушностные признаки и лингводидактические перспективы английского языка как lingua franca (ELF)

УДК 802.0: 37

DOI: $10.21779 / 2542-0313-2017-32-1-37-42$

\title{
M.M. Абдусаламов
}

\section{Сущностные признаки и лингводидактические перспективы английского} языка как lingua franca (ELF)

Дагестанский государственный университет; Россия, 367000, 2. Махачкала, yл. M. I'аджиева, 43a; modolsah@mail.ru

В данной статье с опорой на мнение признанных специалистов рассматриваются уникальный характер феномена «английский язык как lingua franca (ELF)), а также масштабы его функционирования в качестве глобального контактного языка в условиях межкультурной коммуникации. Накоплен большой объем научных исследований этого социолингвистического явления, получены весьма важные результаты. Однако ведущие разработчики этой проблемы указывают на настоятельную необходимость более широкого и активного использования богатых, ценных и многообразных результатов научных исследований в процессе обучения английскому языку. Иначе говоря, наступило время значительно активизировать усилия по разработке лингводидактического аспекта проблемы «английский язык как lingua franca (ELF)». Для этого в первую очередь необходимо решить создавшееся противоречие между (нормоцентрической») методологией обучсния языкам и современными социолингвистическими реальностями. В настоящее время ситуация существенно меняется, но практика обучения языку, почти исключительно основанная на внсдрении норм ограничснного числа территориальных вариантов английского языка (британский и американский), пока сщс не изменилась. Между тем накопленные результаты научных разработок по этой проблеме дают достаточные основания для пересмотра существующей методической концепции. Создавшаяся проблема обусловлена двумя основными причинами, рассматриваемыми в данной статье.

Ключевые слова: «нормочентрическая» методология обучения языкам, глобальный, контактный язык, варианты английского языка.

Со второй половины XX века стал все более зримым начавшийся процесс неуклонного усиления позиций английского языка в мире, который за исторически непродолжительный срок обрел все признаки особого типа lingua franca и завершился формированием версии, известной под названием «английский язык как lingua franca) (English as a lingua franca - ELF). Естественно, возрастает интерес ученых к этому явлению. Начиная со «стартовых» исследований Дж. Дженкинс [1] и Б. Зайдлхофер [3], посвященных этой теме, ELF стал постепенно приобретать признаки отдельной исследовательской парадигмы. За последние полтора десятилетия существенно увеличилось число экспериментальных и теоретических разработок по различным аспектам этой версии английского языка. Более того, стали образовываться специальные центры его исследования. В европейском ареале таким центром стал Хельсинкский университет. В Гонконге активно разворачивается исследование азиатской версии английского языка. На определенном этапе было налажено издание специального научного журнала (Journal of English as a Lingua Franca), начали созываться ежегодные международные конференции (в 
Абдусаламов M.M. Сушностные признаки и лингводидактические перспективы английского языка как lingua franca (ELF) Ястребоб-Пестрицкий М.C. Тексты дореволюционшых и современшых газет: их лингвистические особенности и различия

2015 г. в Пекине, в 2016 г. в Льейде, в 2017 г. планируется в Хельсинки). Кроме того, изданы многочисленные сборники научных работ, посвященные различным аспектам ELF [2, 6, 11].

В нашей стране набллюдается определенный интерес к теоретическому осмыслению глобализации английского языка и ее последствий. Сошлемся лишь на несколько публикаций последних лет. Одна из них посвящена общей характеристике процесса глобализации английского, который привел к образованию региональных, локальных версий (т. н. World Englishes по определению Б. Качру) и глобальной версии, называемой lingua franca [12]. О.В. Казакова анализирует некоторые особенности мелодической организации вариантов английского языка в Индии и Гонконге [13, с. 57-58]. А.В. Аликина, Е.С. Гриценко рассмаривают глобальную версию английского языка в специфическом проявлении «как смыслорождающий ресурс в российском дискурсе трудоустройства» [14, с 52-53]. Н.Г. Аветисян также анализирует глобальный английский язык на российской почве [15, с. 98-109]. В.И. Бондаренко рассматривает этот феномен как лингводидактическую проблему [17].

Тем временем на разных континентах наблюдается мотивация к массовому овладению английским языком в версии lingua franca (ELF). Это означало появление у данного процесса лингводидактического аспекта, поскольку очевидно, что спонтанный процесс «самодеятельного» овладения ELF в самых разных его локальных проявлениях должен постепенно переводиться на научно обоснованный фундамент. Кроме того, накопленный в результате масштабной разработки этой проблемы в разных частях света большой и разнообразный материал послужил весьма ценным подспорьем для начала практической реализации целей и задач обучения ELF.

Однако здесь теоретики и практики натолкнулись на серьезные проблемы. Первая из них связана с уникальной природой самой версии «английский язык как lingua franca» (ELF). Она заключена не в факте использования английского языка в качестве lingua franca. Как известно, функцию контактного средства в межкультурной коммуникации в локальных или региональных масштабах выполняли и ныне выполняют разные языки. Уникальный же характер английского языка в этой функции в современном мире заключается в трансконтинентальных масштабах его использования и превращении самого этого языка, по определению М. Дьюи, в «истинно глобалистский феноменон» [6, с. 3]. Ввиду многоликости самого феномена «английский язык как lingua franca» существуют разные толкования его природы. Приведем характерное в этом отношении определение А. Кого и М. Дьюи. Эти авторы считают необходимым рассматривать его на трех уровнях: «на 1-м уровне - как контекстуальное окружение речевой ситуации, на 2-м как само практическое общение, происходящее в условиях этого контекстуального окружения, на 3-м - как объект научного анализа» [6, с. 2].

B.Е. Бондаренко считает, что, с одной стороны, lingua franca как разновидность World Englishes может рассматриваться как самостоятельная языковая форма, с другой - «это функция английского языка, который выступает в качестве языка-посредника в различных языковых ситуациях и сферах взаимодействия. Таким образом, в результате реализации английским языком функции lingua franca 
Абдусалалов M.M. Сушностные признаки и лингводидактические перспективы английского языка как lingua franca (ELF)

образуется речевой продукт, часто не соответствующий нормам SE (Standard English). Английский как иностранный (English as a Foreign Language, EFL) и Standard English демонстрируют значительные различия даже в пределах одного функционального стиля» [17, с. 44].

Уникальность и сложность этого явления в не меньшей степени обусловлены и спецификой протекания на нем коммуникативного процесса: необычайное разнообразие лингвокультурной среды, распространение коммуникативной среды за традиционно установленные социолингвистические границы; иноязычная, инокультурная принадлежность преобладающей части реальных коммуникантов на ELF, представляющих беспрецедентно широкое лингвокультурное многообразие на всех континентах; «текучесть» (fluidity) условий формирования отношений между коммуникантами и коммуникативным контекстом; широкое использование коммуникантами специфических (локальных, лингвокультурных и др.) условий, их гибкая адаптация к коммуникативным целям и речевой ситуации, с вовлечением в речь локализмов, регионализмов и иных «экзотических» языковых форм и средств; построение речи с ориентацией на конкретного партнера общения; частое переключение языковых кодов, гибкое использование языковых ресурсов (в том числе нестандартных) для усиления коммуникативного эффекта.

$\mathrm{B}$ настоящей статье задачей не является рассмотрение всех специфических деталей ELF. При необходимости можно сослаться на имеющиеся источники, и в первую очередь, на исследование Дж. Дженкинс, А. Кого и М. Дьюи, в которых содержится обширный теоретический и практический материал по этому вопросу [2, c. 281-315].

Вторая не менее серьезная проблема может быть сформулирована как нестыковка вышеприведенных базовых признаков ELF с господствующей в современном мире концепцией обучения иностранным языкам.

Как известно, она всецело и повсеместно ориентирована на стандарты и нормы литературного английского языка (в первую очередь на британский и американский территориальные варианты (Standard British English и Standard American English). Для подтверждения этого вывода приведем результаты изучения этой проблемы известным специалистом в области английского языка как lingua franca на основе проведенных им экспериментов, изучения учебных программ и другой документации, бесед с преподавателями языка [5]. Эта раб̄ота подтвердила, что в условиях обучения второму языку грамматика в основном является предпосылкой для осуществления коммуникативного процесса. Иначе говоря, правильное употребление грамматических правил признается важным фактором при определении успешности коммуникативного процесса. Соответственно понимание иноязычной речи находится в зависимости от соблюдения говорящим нормативных требований языка. Проще говоря, если хотите, чтобы вас понимали, строго соблюдайте установленные нормы Standard British English и/или Standard American English. Кроме того, большое значение придается различного рода тестовым оценкам результатов обучения языку. Это в дальнейшем приводит к тому, что процесс обучения становится ориентированным на такого рода тестовые проверки. На практике точное соблюдение норм и стандартов языка (как правило, Standard British English и/или Standard American English) становится важнейшим 
Абдусаламов M.M. Сушностные признаки и лингводидактические перспективы английского языка как lingua franca (ELF) Ястребоб-Пестрицкий М.C. Тексты дореволюционшых и современшых газет: их лингвистические особенности и различия

критерием при оценке языковой компетенции. При этом такой критерий фактически тесно увязывается с целью выявления того, кто является (или не является) носителем данного языка. Для реально существующего многообразия «глобализирующегося» английского языка здесь нет места [6].

С другой стороны, практика обучения английскому языку как иностранному по «нормоцентрическому» принципу мало способствует практической подготовке обучающихся к успешному общению на ELF.

Между тем большинство разноязычных людей на разных континентах, мотивированных на овладение навыками использования английского языка, не являются носителями этого языка и по необходимости обращаются к нему как к контактному средству в условиях межкультурной коммуникации. Учитывая это, нет необходимости повсеместно ориентировать обучающихся с разной мотивацией и разными целями овладения английским языком на строгое соблюдение стандартов и норм, заложенных в Standard British English и/или Standard American English.

Исследуя процесс овладения английским языком в версии ELF, специалисты пришли к выводу, что по мере того как обучающиеся начинают лучше овладевать английским, они становятся активнее и нередко используют доступные для них ресурсы (инновационные способы), стремясь полнее соответствовать требованиям конкретной речевой ситуации. В противоположность существующей «нормоцентрической» практике обучения языку большая коммуникативная успешность часто отмечается у тех, кто более внимательно прислушивается к речи собеседника, запоминает важные элементы ее структуры и лексическое наполнение и соответственно адаптирует свою речь.

Сложившееся положение вещей практически выводит такую ныне общепризнанную реальность, как глобально распространенный ELF, за рамки теории и методики обучения языку. Это чревато серьезными последствиями, поскольку игнорируются социолингвистические реальности трансконтинентальных масштабов.

Наиболее авторитетные специалисты в этой области настойчиво отмечают необходимость сосредоточить согласованные усилия ученых, университетов и преподавательского корпуса на: 1) активное и повсеместное использование большого массива ценных результатов научного исследования различных аспектов ELF в практике обучения языку; 2) пересмотр существующей «нормоцентрической» теории и практики обучения английскому языку с учетом результатов многочисленных научных исследований по проблемам ELF и ориентируясь на конкретные цели и условия обучения.

Речь идет о том, чтобы английский язык как lingua franca (ELF) нашел свое место в доминирующей в мире теории и практике обучения ИЯ, что многим его исследователям представляется вполне актуальным $[6,14]$. В этом направлении, безусловно, имеются определенные достижения, в частности, отмеченные в недавно опубликованной статье Курта Кона [14].

Таким образом, английский язык в роли lingua franca (ELF), этот «истинно глобалистский феноменон» является одним из притягательных объектов для экспериментальных и теоретических разработок лингвистического, социолингвистического и лигвокультурологического характера. По результатам исследований, 
проведенных за последние полтора десятилетия, накоплен значительный объем ценного материала, закономерно открывший для ELF вход в плоскость лингводидактики. Однако, как с тревогой отмечают ведущие специалисты в этой области, сущностные черты ELF противоречат доминирующей «нормоцентрической»концепции обучения языкам. Это серьезно мешает адекватной реакции на глобальную мотивацию для массового овладения этой версией английского языка в качестве контактного средства межъязыковой и межкультурной коммуникации.

\section{Литература}

1. Jenkins Jennifer. The Phonology of English as an International Language. Oxford: $\quad$ Oxford University 2000. www.researchgate.net/publication/264413126_The_Ph

2. Jenkins Jennifer, Alessia Cogo \& Martin Dewey. Review of developments in research into English as a lingua franca // Language Teaching: Surveys and Studies. 2011. - № 44 (3). - P. 281-315.

3. Seidlhofer Barbara. Closing a Conceptual Gap: the case for the description of English as a lingua franca // International Journal of Applied Linguistics. - Vol. 11, № 2. - P. 133-1584.

4. Seidlhofer Barbara. Understanding English as a lingua franca. - Oxford: Oxford University Press, 2011.

5. Dewey Martin Towards a Post-normative Approach: Learning the Pedagogy of elf // Journal of English as a Lingua Franca. - 2012. № 1 (1). - P. 141-170.

6. Dewey Martin. Pedagogic Criticality and English as a Lingua Franca. https://yandex.ru/search/?text $=$ Martim\%20Dewey.Pedagogical\%20criticality\&lr $=28$ // Revista de la Asociacion Espanola de Estudeos Anglo-Norteamericanos. - 2014. Vol.??? № 2 Diciembre

7. Mauranen Anna and Elina Ranta. English as a Lingua Franca: Studies and Findins. - Newcastle: Cambridge and Scholars, 2009.

8. Bayyurt Yasemin and Sumru Aksaneds. Current Perspectives on Pedagogy for English as a Lingua Franca. - Berlin: De Gruyter Mouton, 2014.

9. Bayyurt Yasemin \& Nicos Sifakis. Developing an ELF-aware pedagogy: Insights from a selfeducation programme // Paola Vettorel (ed.). New frontiers in teaching and learning English. Newcastle upon Tyne: Cambridge Scholars Publishing, 2015. P. 55-76.

10. Kirkpatrick Andy. (2010). English as a Lingua Franca in ASEAN: A Multilingual Model https://books.google.ru/books/about/English_as_a_Lingua_ Franca in ASEAN.ht

11. Cogo Alessia \& Martin Dewey. Analysing English as a lingua franca: A corpus-driven investigation. - London: Continuum, 2012.

12. Абдусаламов М.M. В каком обличии «глобализируется» современный английский язык? // Вестник Дагестанского государственного университета. Cep. 2: Гуманитарные науки. - 2016. - Вып. 2. - С. 69-74.

13. Казакова O.B. Некоторые особенности мелодической организации вариантов английского языка в Индии и Гонконге // Вестник Российского государственного лингвистического университета. Сер.: Языкознание и литературоведение. - 2015. - Вып. 1 (712). - С. 57-58.

14. Аликина A.B., Грищенко E.C. Английский язык как смыслорождающий ресурс в российском дискурсе трудоустройства // Вестник Российского государственного лингвистического университета. Сер.: Языкознание и литературоведение. - 2015. - Вып. 6 (717). - С. 52-53. 
Абдусаламов M.M. Сушностные признаки и лингводидактические перспективы английского языка как lingua franca (ELF) Ястребоб-Пестрицкий М.C. Тексты дореволюционшых и современшых газет: их лингвистические особенности и различия

15. Аветисян Н.Г. Английский язык в российской действительности: нашествие или результат глобализации? // Вестник Московского государственного университета. Сер.: Язык. Познание, Культура. - 2016. - Вып. 4. - С. 98-109.

16. Mauranen Anna. Review of Exploring ELF // Academic English Shaped by Non-native Speakers, $2012 \mathrm{http}: / /$ www.academia.edu/8329511/Review of Exploring_ELF_Academic_English_Shaped_by_Nonnative_Speakers_Anna_Maūrā̄en.

17. Бондаренко B.И. Lingua franca как лингводидактическая проблема: традиции и инновации // Вестник МГЛУ. - 2013. - Вып. 14 (674). http://www.sprachlernmedien.de/wp- content/uploads/2016/07/Kohn-2016_From-ELFcommunication-to-lingua-franca - pedagogy_pre-publ.pdf.

18. Kohn Kurt. From ELF communication to lingua franca pedagogy, University of Tübingen // Pitzl Marie-Luise \& Ruth Osimk-Teasdale (eds.) English as a Lingua Franca: Perspectives and Prospects: Contributions in Honour of Barbara Seidlhofer. Boston/Berlin: De Gruyter Mouton. 2016. P. 87-96.

UDC 802.0: 37

Поступила в редакиию 2 марта 2017 2.

DOI: $10.21779 / 2542-0313-2017-32-1-37-42$

\section{Basic features and pedagogy of English as a lingua franca (ELF)}

\section{M.M. Abdusalamov}

Dagestan State University; Russia, 367001, Makhachkala, M. Gadzhiev st., 43a; modolsah@mail.ru

The article considers unique features of a phenomenon termed "English as a lingua franca (ELF)" and an unprecedented scale to which it has been disseminated in the world. In fact it functions as a global means of intercultural communication. Today leading experts in this phenomenon have been persistently drawing readers' attention to an urgent necessity of a wider application of abundant, valuable and various research findings in ELF for language pedagogy. Time has come to resolve the conflict between dominating "norm-centred" language teaching methodology and contemporary sociolinguistic realities. The situation has now changed dramatically, but current practice in ELT, based practically exclusively-on the promotion of the norms of a limited number of varieties (British and American English), has not yet moved on very far. Meanwhile, the mentioned findings provide sufficient ground for reconsideration of "normcentred" language teaching methodology which leaves little scope for an appreciation of linguistic diversity. The problem is preconditioned by two basic reasons considered in this article.

Keywords: "norm-centred" language pedagogy, global, contact language, variants of the English language.

Received 2 March, 2017 